\title{
Análise cienciométrica da produção científica sobre turismo alternativo nas Américas entre 1973 a 2017
}

\section{Scientometric analysis of scientific production on alternative tourism in the Americas from 1973 to 2017}

\author{
Heloise Michelle Nunes Medeiros \\ Universidade Federal do Oeste do Pará, Brasil \\ heloise_medeiros28@hotmail.com \\ Quêzia Leandro de Moura Guerreiro \\ Universidade Federal do Oeste do Pará, Brasil \\ queziamoura@hotmail.com \\ José Max Barbosa Oliveira-Junior \\ Universidade Federal do Oeste do Pará, Brasil \\ jose.mbo@ufopa.edu.br
}

\begin{abstract}
Resumo
Este trabalho avaliou a produção de artigos científicos sobre turismo alternativo desenvolvidos no Continente Americano publicados no período de 1973 a 2017, através de uma análise cienciométrica. A pesquisa de artigos foi realizada nas bases de dados ISI Web of Knowledge, Scopus Database e Scielo. Foram tabulados 4.137 artigos para análise da tendência espacial e temporal, e a partir destes foram determinados os periódicos que mais publicaram sobre o tema, os segmentos do turismo alternativo mais citados, as temáticas mais abordadas, a quantidade de trabalhos realizados em áreas protegidas, o caráter dos impactos ambientais e os ambientes mais afetados. Observa-se que é necessário desenvolver cada vez mais o turismo alternativo de maneira a respeitar a essência deste segmento, nomeadamente o desenvolvimento sustentável com envolvimento e valorização das comunidades e tradições locais, incorporando-as ao setor econômico e promovendo a educação ambiental.
\end{abstract}

Palavras-chave: Continente Americano; alterações ambientais; publicações; tendência espacial e temporal; turismo alternativo.

\begin{abstract}
This work evaluates the production of scientific articles on alternative tourism developed in the American continent that were published from 1973 to 2017, through a scientometric analysis. The search was carried out in the ISI Web of Knowledge, Scopus Database and Scielo databases. 4,137 articles were tabulated to analyze the spatial and temporal trend, and from these the following aspects were determined: the journals that published the most on the theme, the most cited segments of alternative tourism, the most covered themes, the amount of work carried out in protected areas, the character of environmental impacts and the most impacted environments. It is observed that it is necessary to develop more alternative tourism in order to respect what the essence of the segment requires, such as sustainable development, with involvement and
\end{abstract}

Dos Algarves: A Multidisciplinary e-Journal, 39-2021.

ISBN 2182-5580 @ ESGHT - University of the Algarve, Portugal.

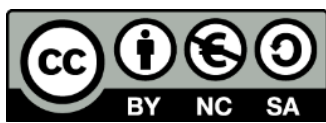

To cite this article: Medeiros, H. M. N., Guerreiro, Q. L. de M. \& Oliveira-Junior, J. M. B. (2021). Análise cienciométrica da produção científica sobre o turismo alternativo nas Américas entre 1973 a 2017. Dos Algarves: A Multidisciplinary e-Journal, 39, 71-94. DOI: 10.18089/DAMeJ.2021.39.5 
appreciation of local communities and traditions, incorporating them into the economic sector and promoting environmental education.

Keywords: Amercian continent; environmental changes; publications; spatial and temporal trends; alternative tourism.

\section{Introdução}

Os estudos realizados em turismo alternativo e as suas conotações ainda são incipientes (Costa, 2016; Faco, 2013; Meng, Jun \& Zhengzheng, 2009). Não existe nas bases de dados (Scielo, Scopus e Web Of Science) um estudo cienciométrico sobre o turismo alternativo nas Américas, por exemplo. O presente trabalho avaliou a produção de artigos científicos sobre o turismo alternativo e os seus impactos ambientais no Continente Americano entre 1973 a 2017.

O turismo alternativo se realiza nos segmentos turísticos denominados de ecoturismo, turismo cultural, turismo de aventura, turismo de natureza, turismo sustentável, turismo acadêmico, turismo rural, dentre muitas outras formas já investigadas (Pires, 2017; Wearing \& Neil, 2014), que integram no seu campo de atuação, as preocupações e demandas de movimentos sociais e ambientalistas (Coriolano \& Sampaio, 2012). Existem diferentes conceitos/definições de turismo alternativo na literatura, no entanto, há uma característica que é constante em todas elas, ser considerada uma modalidade turística que se opõe ao turismo de massa e aproxima o relacionamento dos turistas com a natureza (Barrio, Maquiera, Fernández \& Chavez, 2020). O turismo alternativo prima pelo desenvolvimento sustentável e busca uma mudança de paradigma, pois incentiva novas formas de pensar e fazer o turismo, com a preocupação de não esgotar os recursos naturais e culturais e que as populações tradicionais participem do planejamento e dos lucros (Bringas \& González, 2004). Klak (2007) também afirma que o turismo alternativo tende a contrastar com o turismo de massa, em várias dimensões, por exemplo, no turismo alternativo a escala tende a ser menor e uma maior parcela de insumos é local, adicionalmente, os turistas tendem a ser mais ativos fisicamente e interagir mais com a cultura local nos seus próprios termos.

Tais segmentos acarretam impactos ambientais positivos como a criação de áreas protegidas e programas de estímulo ao orgulho étnico das tradições locais, mas também podem interferir negativamente quando o turista, por exemplo, alimenta os animais ou quebra a vegetação das margens das trilhas, ou polui os ambientes frequentados com resíduos (Ruschmann, 2003). Para que o turismo alternativo alcance o seu objetivo é necessário planejamento, regulamentação e fiscalização dos empreendimentos, definição da capacidade de carga, promoção da atração de recursos humanos, e realização de estudos de impacto ambiental (Beni, 2017).

O turismo é um recente campo de estudos e pesquisas das Ciências Sociais Aplicadas. $O$ primeiro estudo com a finalidade de observar a produção de conhecimento sobre turismo foi o trabalho de Jafari e Aaser (1988), que elencaram as teses de doutorado defendidas nos Estados Unidos no período de 1951 a 1987, analisando a evolução temporal, os programas e as instituições produtoras dos estudos. Este trabalho estimulou a pesquisa de Rejowski (1993) desenvolvida no Brasil, que listou 55 dissertações de mestrado e teses de doutorado 
sobre o turismo no período de 1975 a 1992. Internacionalmente, o objeto de estudo dessas pesquisas expandiu-se para os periódicos científicos (Alberton \& Lopes, 2007; Bertuzzo, 2004; Pechlaner, Zehrer, Matzler, \& Abfalteral, 2004; Shen et al., 2018; Zhang, Lyu \& Yan, 2015).

O estudo cienciométrico é "um instrumento criado por pesquisadores da Ciência da Informação, voltado exclusivamente para estudos da comunicação científica" (Bertuzzo, 2004: 2). Os dados quantitativos sobre periódicos e artigos científicos obedecem a regras, configurando-as como indicadores do estado da ciência (Vanti, 2002). Estes indicadores científicos surgem da mensuração dos resultados de pesquisas científicas, de modo a permitir a formulação de técnicas interdisciplinares, utilizadas pelas áreas de Economia, da Estatística, da Administração e da documentação (Bufrem \& Prates, 2005).

O periódico científico é o canal de distribuição da informação mais usado pelos pesquisadores, então, os trabalhos, uma vez publicados em revistas científicas, são passíveis de verificação de sua conformidade, originalidade e importância, pois passaram por um processo de avaliação e aprovação.

Neste contexto, a presente pesquisa realizou uma análise cienciométrica dos artigos disponíveis em periódicos, veiculados nas principais bases de dados mundiais, que abordavam o turismo alternativo, para estabelecer a evolução temporal do número de publicações, os países do Continente Americano mais estudados, os periódicos que mais publicaram, os ambientes e impactos mais relatados.

\section{Material e métodos}

\subsection{Tipo de estudo}

A pesquisa caracteriza-se como um estudo cienciométrico, que trata os aspectos quantitativos da ciência enquanto disciplina ou atividade econômica em que os artigos selecionados foram agrupados em categorias para responder aos objetivos da pesquisa (Vanti, 2002). Cada literatura foi categorizada utilizando os principais indicadores cienciométricos de importância no cenário nacional e internacional, como os países e revistas que mais publicam (Macias-Chapula, 1998) sobre o tema turismo alternativo e impactos ambientais.

\subsection{Coleta de dados}

Foi realizada uma busca dos artigos científicos publicados nos últimos 45 anos (1973 a 2017) que abordaram o tema turismo alternativo e impactos ambientais em áreas do Continente Americano (Norte, Central e Sul). Esse recorte espacial foi definido devido à importância ímpar do turismo no Continente Americano, o qual ocupa o terceiro lugar na classificação mundial de destinos do turismo internacional. Em 2017, as 211 milhões de entradas internacionais no Continente Americano representaram 16\% das entradas do turismo mundial (Organização Mundial do Turismo [OMT], 2018). Andreu-Boussut e Salin (2018) apontam que alguns países das Américas dispõem, também, de um turismo interno altamente desenvolvido. 
Para o recorte temporal foi determinado a década do surgimento do turismo alternativo (1970), pois nesse momento foram criadas formas de turismo nos moldes do desenvolvimento sustentável (Bringas \& González, 2004). Nesse período, as pesquisas envolvendo o turismo em espaços americanos tiveram contribuição das ciências sociais, possibilitando a expansão do campo dos estudos de turismo/tourism studies (AndreuBoussut \& Salin, 2018).

A pesquisa foi feita nas bases de dados Scopus Database (Elsevier), Scielo (Scientific Electronic Library) e Web Of Science (Thompson Reuters). O acesso ocorreu através do Portal de Periódicos da Coordenação de Aperfeiçoamento de Pessoal de Nível SuperiorCAPES. A seleção destas bases de dados deve-se ao seu grande impacto na ciência. A Web of Science (Thompson Reuters), a ferramenta disponível de indexação de literatura científica mais reconhecida internacionalmente, fornece importantes dados sobre as mais diferentes áreas de pesquisas em ciências e tecnologia (Pereira et al., 2018). A Scopus Database (Elsevier) tem apresentado um aumento significativo no número de artigos indexados nas últimas quatro décadas (Alves, Teresa \& Nabout, 2014) e a Scielo foi adicionada por abranger trabalhos locais e/ou regionais, e publicar mais de 380 revistas científicas de temáticas variadas (Puccini, Giffoni, Silva \& Utagawa, 2015). Todas têm sido utilizadas com frequência em estudos cienciométricos (Nicacio \& Juen, 2015; Pereira et al., 2018; Shimano, Salles \& Juen, 2013).

Os termos utilizados na pesquisa, em cada base de dados e nos idiomas, português, inglês e espanhol foram descritos por Pires (2017) (Quadro 1). Os artigos que possuíam os termos nos títulos, resumos e palavras-chave foram importados para um banco de dados. Foram excluídas da análise as pesquisas que não foram desenvolvidas no Continente Americano, assim como os resumos de congressos e conferências, livros e capítulos de livros e editoriais.

Quadro 1. Termos utilizados nas bases de dados Scopus, Scielo e Web Of Science para busca das publicações sobre turismo alternativo no Continente Americano, entre os anos de 1973 a 2017. n.a.= não se aplica

\begin{tabular}{|c|c|c|}
\hline Português & Inglês & Espanhol \\
\hline Agroecoturismo & Agroecotourism & n.a. \\
\hline Agroturismo & Agrotourism/Agritourism & n.a. \\
\hline Cicloturismo & Bicycle touring & Ciclismo \\
\hline Ecoaventura & Ecoventure & n.a. \\
\hline Ecocaminhada & Ecotripping & n.a. \\
\hline Ecoturismo & Ecotourism & n.a. \\
\hline Turismo acadêmico & Academic tourism & Turismo académico \\
\hline Turismo alternativo & Alternative tourism & n.a. \\
\hline Turismo ambiental & Environmental tourism & n.a. \\
\hline Turismo antropológico & Anthropological tourism & n.a. \\
\hline Turismo apropriado & Appropriate tourism & n.a. \\
\hline Turismo arqueológico & Archaeological tourism & n.a. \\
\hline
\end{tabular}




\begin{tabular}{|c|c|c|}
\hline Português & Inglês & Espanhol \\
\hline Turismo científico & Scientific tourism & n.a. \\
\hline Turismo comunitário & Community tourism & Turismo comunitario \\
\hline Turismo cultural & Cultural tourism & n.a. \\
\hline Turismo de aventura & Adventure tourism & n.a. \\
\hline Turismo de baixo impacto & Low impact tourism & Turismo de bajo impacto \\
\hline Turismo de esportes & Sports tourism & Turismo de deportes \\
\hline Turismo de natureza & Nature tourism & Turismo de naturaleza \\
\hline Turismo de risco & Tourism of risk & Turismo de riesgo \\
\hline Turismo de solidariedade & Solidarity tourism & Turismo de solidaridad \\
\hline Turismo ecológico & Eco tourism & Turismo ecológico \\
\hline Turismo eco-rural & Eco-rural tourism & n.a. \\
\hline Turismo educacional & Educational tourism & Turismo educativo \\
\hline Turismo ético & Ethical tourism & n.a. \\
\hline Turismo étnico & Ethnic tourism & n.a. \\
\hline Turismo local & Local tourism & n.a. \\
\hline Turismo na floresta & Tourism in the forest & Turismo em el bosque \\
\hline Turismo participativo & Participative tourism & n.a. \\
\hline Turismo planejado & Planned tourism & Turismo planeado \\
\hline Turismo responsável & Responsible tourism & Turismo responsable \\
\hline Turismo rural & Rural tourism & n.a. \\
\hline Turismo suave & Soft tourism & n.a. \\
\hline Turismo sustentável & Sustainable tourism & Turismo sostenible \\
\hline Turismo verde & Green tourism & n.a. \\
\hline
\end{tabular}

Fonte: Adaptado de Pires (2017).

\subsection{Análise de dados}

Os indicadores cienciométricos foram tabulados considerando cada artigo como uma amostra (Mooghali, Alijani, Karami \& Khasseh, 2011). Os dados foram analisados através de análises de frequência simples com intuito de verificar a ocorrência de trabalhos. Os resultados foram expressos em gráficos dos principais tipos de ambientes estudados, abordagens de estudos, periódicos de publicações, áreas protegidas, mapa do Continente (tendência espacial) e fluxograma dos principais segmentos de turismo alternativo.

Para avaliar a relação entre o número e ano de publicação (tendência temporal) foi realizada uma correlação de Pearson (Figueiredo-Filho \& Silva Júnior, 2009). Para medir a diversidade de periódicos que publicaram artigos sobre turismo alternativo foi realizado o índice de Shannon-Wiener $\left(\mathrm{H}^{\prime}\right)$. Para testar as diferenças entre trabalhos desenvolvidos em ambientes terrestre e aquático utilizou-se o teste T de student (Barbosa \& Souza, 2010). Para avaliar a diferença significativa entre o caráter dos impactos ambientais foi realizada uma Análise de Variância (ANOVA) (Marôco, 2018).

Todas as análises foram realizadas pelas rotinas do programa R ( $R$ Development Core Team, 2015) utilizando o pacote vegan. 


\section{Resultados e discussão}

Um total de 10.596 trabalhos foi importado das bases de dados. Devido à abrangência dos termos utilizados, 4.096 estavam repetidos e foram excluídos, pois, no mesmo artigo foram encontrados mais do que uma das palavras-chave, como, por exemplo, ecoturismo e turismo de natureza. Portanto, 6.500 artigos foram inicialmente analisados e desses, 4.137 atenderam aos objetivos do trabalho.

\subsection{Tendências espaciais das publicações}

Os trabalhos foram realizados em 36 países do Continente Americano (Norte, Central e Sul) (Figura 1). A América do Norte foi o continente com o maior número de publicações ( $\mathrm{N}=2.225$; 47,5\%), sendo a contribuição dos Estados Unidos, a mais expressiva ( $N=1.231 ; 26,3 \%)$. Para a América do Sul ( $\mathrm{N}=1.573 ; 33,7 \%)$, segunda área com maior número de artigos, o Brasil foi o país com maior representação ( $\mathrm{N}=748 ; 16 \%)$. Por último, a América Central ( $\mathrm{N}=882 ; 18,8 \%$ ), com a Costa Rica como principal local alvo das publicações ( $N=192 ; 4,1 \%$ ) (Figura 1).

A maior participação dos Estados Unidos no total de artigos pode ser justificada por três fatores. Primeiro, esse país abriga centros de pesquisas e grandes Universidades (Texas A\&M University, University of Florida, Arizona State University, University of Illinois, Purdue University e Cornell University) difusoras de conhecimento, que mantém redes de colaboração para realização de estudos sobre o turismo (Güzeller \& Çeliker, 2018; Zhang et al., 2015). O segundo diz respeito à demanda turística deste país, por ser um dos principais emissores de turistas do mundo (87,7 milhões em 2017) e, ao mesmo tempo, responde pela alta demanda de fluxo de turistas internos, e o terceiro fator está relacionado com o alto preparo receptivo de turistas internacionais, sendo 77 milhões de visitantes internacionais somente em 2017 (Pimentel, Carvalho \& Oliveira, 2018).

No caso do Brasil, segundo país estudado com o maior número de publicações, existem cerca de 57 Centros de Pesquisa em instituições de ensino especializadas em estudos com turismo (Pimentel et al., 2018) e a demanda internacional do Brasil, no ano de 2018, atingiu o seu maior registro de chegadas (1,035 milhões de turistas) (Ministério do Turismo do Governo Federal do Brasil, 2018a). Muitos governos, incluindo o Brasil, reconhecem o papel importante do turismo no desenvolvimento da economia nacional devido ao impacto positivo que o turismo pode ter na geração de empregos e receita tributária (Mariutti, Giraldi \& Crescitelli, 2013). Em 2019, o Brasil registrou aproximadamente 6,35 milhões de chegadas de turistas internacionais.

A Costa Rica, até 1980, apresentava uma economia, predominantemente agrícola, quando foi reestruturada para uma economia de manufatura e serviços, onde o ecoturismo passou a ser o segmento responsável pelo alto desempenho, expresso na visita aos seus atrativos naturais e aos empreendimentos locais e indígenas (Gunter, Ceddia, Leonad \& Tröster, 2018). As chegadas internacionais têm sido progressivas desde 2014 e atingiram quase três milhões em 2017, ou seja, uma taxa de crescimento de $17 \%$ ao ano, sendo os seus principais países emissores a América do Norte, a própria América Central e a América do Sul (Instituto Costarricense de Turismo [ICT], 2017). Pieri (2014) destaca os fatores negativos que 
limitam o crescimento do turismo internacional em países como El Salvador e Haiti, como problemas ligados a conflitos políticos, forte insegurança relacionada com a atuação de grupos de narcotraficantes e instabilidade climática.

Figura 1. Frequência de países alvo de estudos sobre turismo alternativo dentre as Américas (Norte, Central e Sul) no período de 1973 a 2017

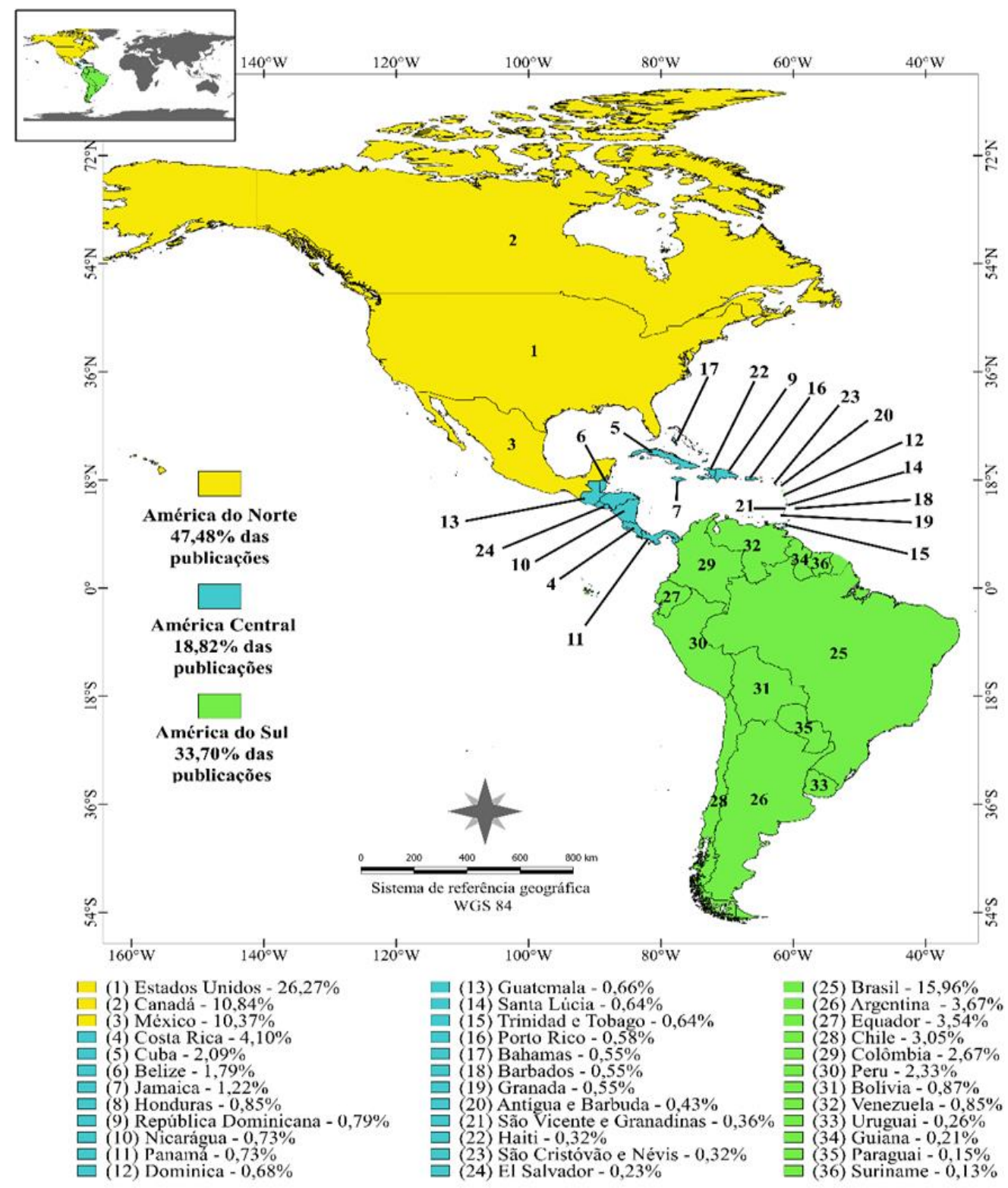

\subsection{Tendencias temporais das publicações}

Existe uma correlação positiva forte entre o número de trabalhos e ano de publicação ( $r=$ 0,$864 ; p<0,001$ ), o que indica um crescimento significativo de publicações ao longo dos anos, sendo a primeira publicação encontrada em 1973 ( $n=1)$, com um acréscimo em $1993(n=43$; 
1\%), picos maiores em $2003(n=104 ; 3 \%)$ que se quadruplicaram em $2016(N=410 ; 10 \%)$ e 2017 $(n=456 ; 11 \%)$ (Figura 2).

Figura 2. Correlação entre o número e o ano de publicação dos trabalhos sobre turismo alternativo no Continente Americano (período de 1973 a 2017)

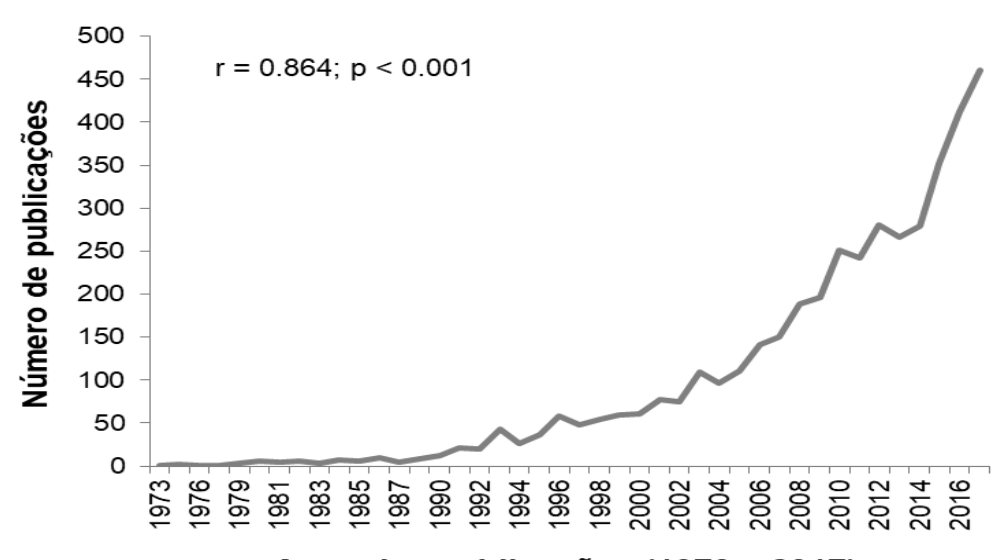

Anos das publicações (1973 a 2017)

O turismo foi institucionalizado como curso acadêmico no Brasil a partir de 1970, mas as primeiras discussões sobre o tema surgiram em 1960 nos países europeus, como a Espanha. A produção científica até esse momento era limitada a dissertações e teses, mas esse período foi importante para as discussões sobre a área, com a realização dos primeiros eventos científicos que discutiam questões sobre a realidade turística brasileira, o mercado de trabalho e as necessidades do setor (Hallal \& Müller, 2014).

Na década de 1970 emergem e se intensificam as visões quanto ao "turismo diferente" (turismo alternativo), em contraposição ao modelo predatório (turismo de massa), e surgem projetos turísticos com características alternativas em várias partes do mundo, que envolviam operações de pequena escala, com ênfase nos recursos da própria localidade (Pires, 2017). Trigo (2005) afirma que a partir desses marcos, na década de 1980, é possível encontrar uma produção científica mais robusta, geradas por universidades e instituições de pesquisas atuantes das ciências sociais, verificados com o aumento das publicações encontradas por estes tipos de instituições.

Na década de 1990 (especificamente em 1993) observou-se um pico de publicações, que pode ser associado à Conferência das Nações Unidas sobre Meio Ambiente e Desenvolvimento em 1992, quando os meios científicos, em geral, despertaram para a abordagem do turismo alternativo como tema, principalmente o Ecoturismo, pois as primeiras discussões sobre o assunto estavam mais direcionadas aos seus sinônimos, como Turismo Ecológico e Turismo de Natureza (Trigo, 2005).

Outro fator que pode ter contribuído para o número expressivo de publicações em 2003 foi a proclamação de 2002 como o Ano Internacional do Ecoturismo, declaração dada pela Sociedade Internacional de Ecoturismo (TIES). Nesse ano também aconteceu a Cúpula Mundial do Ecoturismo, que resultou na Declaração de Quebec, pela qual o tema ecoturismo ganhou ascensão internacional, pois acenava para o crescimento das atividades de ecoturismo implementadas à luz do desenvolvimento sustentável (Quintana, 2017). 
A maior tendência das pesquisas na área do turismo alternativo foi nos anos de $2016 \mathrm{e}$ 2017. Em 2016, a Organização Mundial do Turismo (OMT, 2017) registrou que este foi o sétimo ano seguido de crescimento do segmento, após a crise financeira global de 2009. Em 2017 foi proclamado pela Organização das Nações Unidas para a Educação, a Ciência e a Cultura (UNESCO, 2017) o Ano Internacional do Turismo sustentável, que em números responde por cerca de $10 \%$ da atividade econômica mundial.

\subsection{Periódicos científicos}

Foi encontrada alta diversidade de periódicos que publicaram artigos sobre o turismo alternativo no Continente Americano $\left(\mathrm{N}=1.203 ; \mathrm{H}^{\prime}=4.653\right)$. Os periódicos com maior número de publicações foram Estudios y Perspectivas en Turismo ( $\mathrm{N}=186 ; 15 \%)$, Journal of Sustainable Tourism ( $\mathrm{N}=171 ; 14 \%)$ e Annals of Tourism Research ( $\mathrm{N}=123 ; 10 \%)$ (Figura 3).

Figura 3. Periódicos científicos com maior número de publicações sobre turismo alternativo no Continente Americano (período de 1973 a 2017)

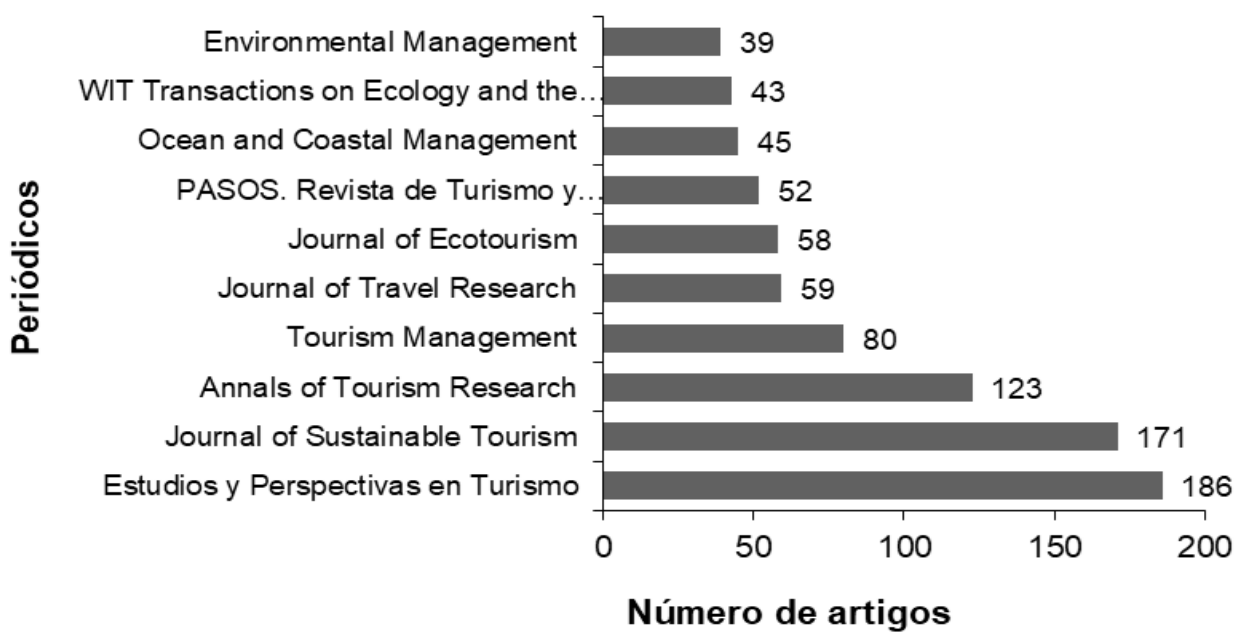

A revista Estudios y Perspectivas en Turismo recebe submissões de artigos referentes a diversos temas do fenômeno turístico, como ambientais, administrativos, econômicos, sociológicos, geográficos, antropológicos e psicológicos, e procura encontrar o equilíbrio entre teoria e prática, bem como construir um campo sólido de conhecimento na área do turismo com base na contribuição de diferentes ciências e disciplinas (Centro de Investigaciones y Estudios Turísticos [CIET], 2015).

O periódico Journal of Sustainable Tourism, que oferece pesquisas teóricas, conceituais e empíricas que exploram aspectos econômicos, sociais, culturais, políticos, organizacionais e ambientais dos grandes temas de turismo relacionados com o desenvolvimento sustentável, em 2018 possuía fator de impacto de 3.400. O Annals of Tourism Research, com fator de impacto de 5.908 no ano de 2019, é uma revista de ciências sociais focada nas perspectivas acadêmicas do turismo. 
Estas características influenciaram os resultados das pesquisas, pois a primeira revista com maior número de publicações sobre o turismo alternativo tem uma abrangência regional e está indexada na base de dados Scielo, a pesquisa se dedicou à análise do Continente Americano, enquanto as outras duas revistas, apesar de terem abrangência mundial, os seus maiores números de publicações apontam para o Continente Europeu, Asiático e Oceania, e são indexados nas bases de dados Scopus e Web of Science (Zhang et al., 2015).

\subsection{Segmentos do turismo alternativo}

Nos trabalhos estudados (Figura 4) foram identificados 34 segmentos relacionados com o turismo alternativo. O segmento mais expressivo nas publicações foi o Ecoturismo ( $\mathrm{N}=1.257$; 30,1\%), seguido de Turismo Cultural ( $N=657 ; 15,7 \%$ ), Turismo Sustentável ( $N=468 ; 11,2 \%$ ), Turismo Rural ( $\mathrm{N}=292 ; 7 \%)$ e Turismo Ecológico ( $\mathrm{N}=267 ; 6,4 \%)$ (Figura 4).

Figura 4. Porcentagens dos segmentos do turismo alternativo encontrados nas publicações do Continente Americano (período de 1973 a 2017)

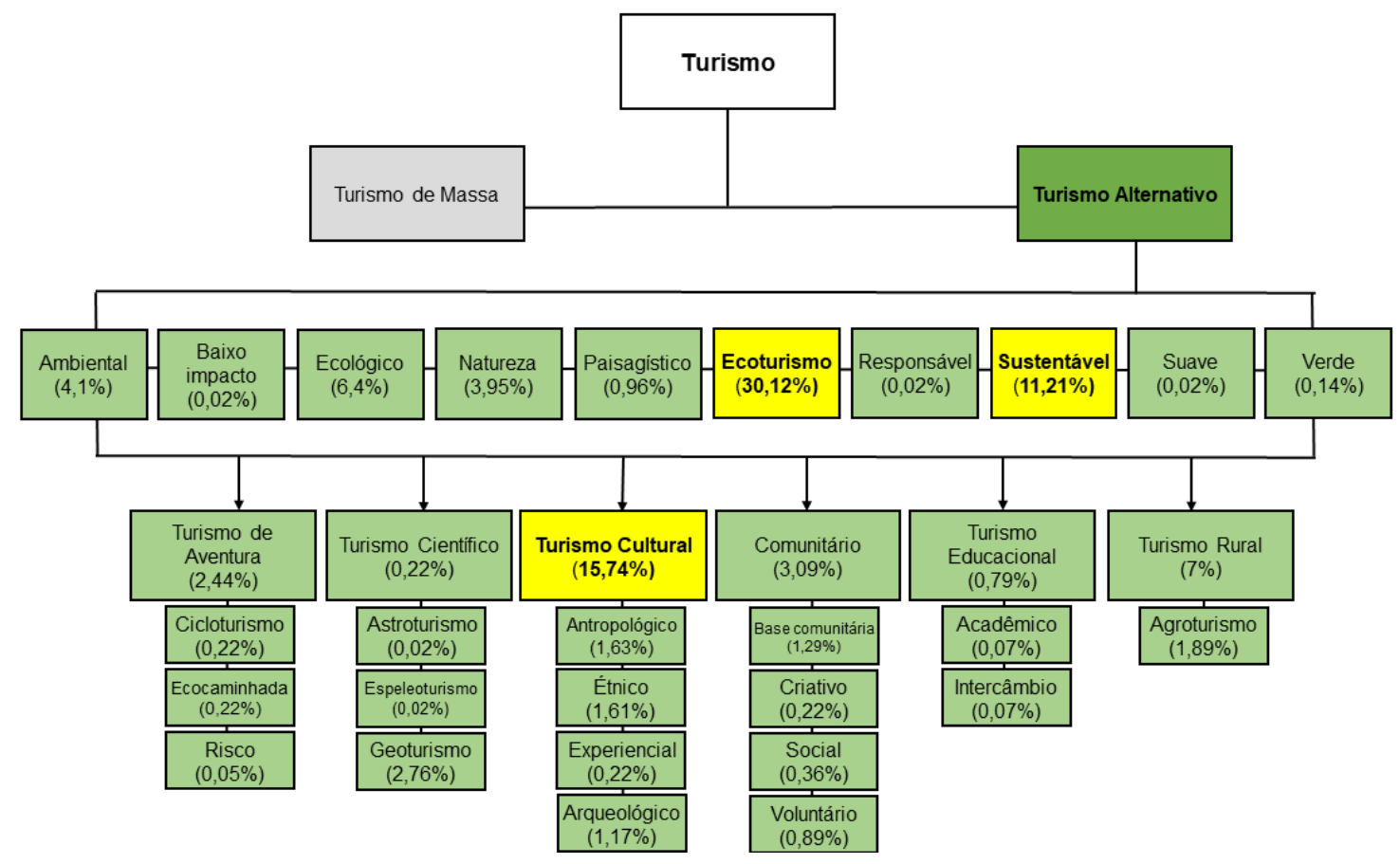

Nota: Caixa verde escuro apenas representa a abordagem desse estudo, ou seja, o turismo alternativo. Caixas amarelas representam os termos mais encontrados (acima de 10\% do total) nas publicações dentro do turismo alternativo.

O ecoturismo foi o segmento mais expressivo como alternativa ao turismo de massa, incorporando na sua concepção todos os princípios do turismo alternativo tendo adquirido identificação própria (Pires, 2017). O ecoturismo se consolida somente a partir da década de 1990, porém o seu conceito foi cunhado em 1983 por Ceballos-Lascuráin, que o preceitua como viagens ambientalmente responsáveis pelas áreas naturais, sem distúrbios, promovendo a conservação, redução dos impactos e contribuição socioeconômica para as 
populações locais; o conceito foi adotado pelo Programa de Ecoturismo da União Internacional para Conservação da Natureza (UICN) e outras organizações como o Fundo Mundial da Natureza (WWF) e Conservação Internacional (Cl) (Pires, 2017).

O ecoturismo se destaca por utilizar, sustentavelmente, o patrimônio natural e cultural através do incentivo à conservação e busca a formação de uma consciência ambientalista através da interpretação do ambiente ou Educação Ambiental, promovendo o bem-estar das populações envolvidas (Spaolonse \& Martins, 2016). Fennell (2003: 25) define ecoturismo como "Uma forma sustentável de turismo baseado em recursos naturais que se concentra principalmente em experimentar e aprender sobre a natureza, e que é administrado eticamente para ser de baixo impacto, não consumir e orientar localmente (controle, benefícios e escala). Normalmente ocorre em áreas naturais e deve contribuir para a conservação ou preservação dessas áreas".

O turismo cultural é abrangente e segundo a Organização Mundial do Turismo (OMT, 2018) é uma atividade turística em que a principal motivação do turista é aprender, descobrir, vivenciar e consumir atrativos/produtos culturais tangíveis e intangíveis num destino turístico. Essas atrações envolvem uma série de características materiais, intelectuais, espirituais e emocionais que são completamente diferentes em toda a sociedade, incluindo arte e arquitetura, patrimônio histórico e cultural, patrimônio culinário, literatura, música, indústrias criativas e a cultura viva e os seus estilos de vida com os seus valores, crenças e tradições.

O terceiro segmento mais encontrado foi o turismo sustentável, geralmente equiparado ao ecoturismo, pois ambos propõem um modelo de turismo planejado para assegurar a sua longevidade, integra as comunidades locais e busca a gestão sustentada dos recursos naturais e culturais (Pires, 2017).

Os segmentos turísticos: paisagístico, de base comunitária, criativo, social, voluntário, intercâmbio, experiencial, astroturismo, espeleoturismo e geoturismo, não constavam na tabela de palavras-chave consideradas no estudo, porém, foram identificadas sob o "guardachuva" do turismo alternativo, que, segundo Dias (2003) tem como característica principal o contato com a natureza e a valorização da cultura local, características implícitas dos segmentos listados.

\subsection{Ambientes de realização dos trabalhos}

Existem diferenças significativas entre o número de trabalhos desenvolvidos em ambientes terrestres e aquáticos ( $T=1,887 ; G . L .=102 ; p=0,050$ ) (Figura 5). Dentre os trabalhos que citaram os ambientes estudados, registrou-se em média 42 trabalhos a mais para ambientes terrestres do que para ambientes aquáticos (Figura 5). 
Figura 5. Ambientes de realização dos estudos com turismo alternativo no Continente Americano no período de 1973 a 2017

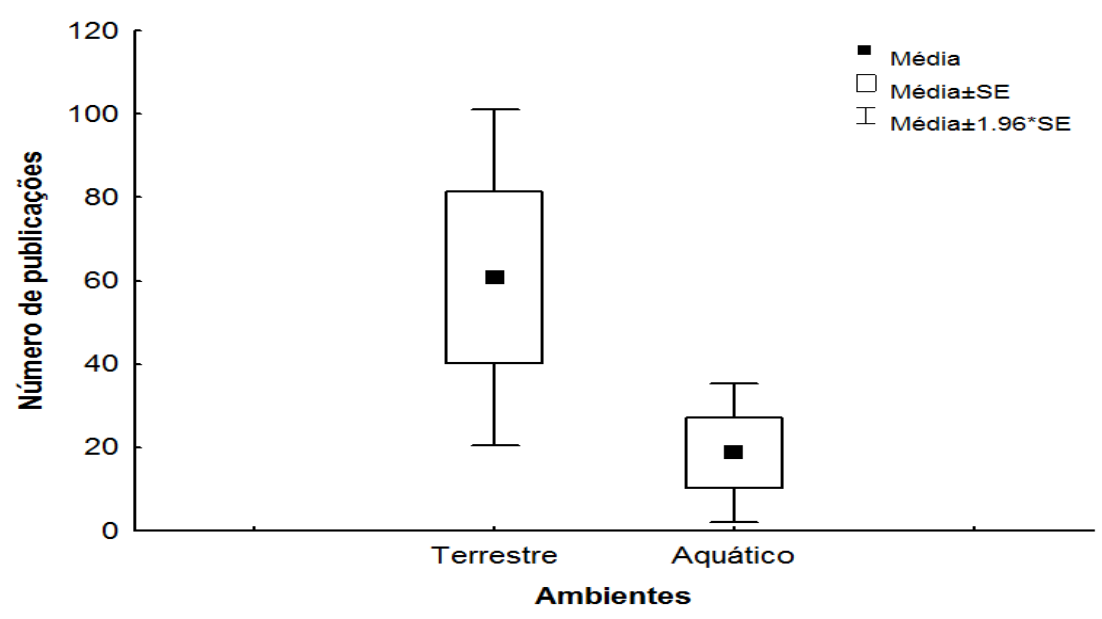

Os trabalhos desenvolvidos no meio terrestre abrangem as áreas de florestas, as comunidades rurais, quilombolas e indígenas, os sítios arqueológicos, os geossítios, as trilhas ecológicas, as matas remanescentes das zonas urbanas, as pousadas, os hotéis-fazenda e os estudos com a fauna e flora terrestres. No turismo alternativo se observa uma variedade de atividades caracterizadas pela relação com a natureza, seja com a fauna, a flora, as formações rochosas, as paisagens e os espetáculos naturais extraordinários (Ministério do Turismo do Governo Federal do Brasil, 2010; Penerliev, 2017).

Os turistas podem percorrer uma trilha para conhecer a flora de determinada região e por sorte conseguir observar os animais que estão pelo caminho, podem também conhecer as comunidades anfitriãs e interagir nas atividades cotidianas ou eventos tradicionais, como forma de valorização do ambiente cultural e dar oportunidade de geração de renda extra às iniciativas sociais comunitárias (Ministério do Turismo do Governo Federal do Brasil, 2010).

Nestes ambientes os estudos de capacidade de carga são importantes para o planejamento e gestão de áreas naturais. Desse modo é possível definir indicadores e o manejo de áreas onde ocorrerá a visitação, para um melhor uso do solo e a mitigação dos impactos negativos nos recursos naturais, bem como em relação à perda da qualidade da experiência do turista, haja vista ser necessário o monitoramento contínuo, pois as condições se modificam (Leão, 2018).

No ambiente aquático as áreas de estudos foram em recifes de coral, zonas húmidas, arquipélagos, lagos, rios, oceano, litoral, trilhas marinhas, quedas d'água, cataratas, manguezais, áreas protegidas marinhas e fauna marinha. Foi observado menor expressividade de trabalhos nesta área, apesar de o ambiente aquático ser um dos ecossistemas que mais sofre impactos antrópicos, por se constituir no destino final de vários produtos (Akaishi, 2003). 


\subsection{Trabalhos realizados em áreas protegidas}

Do total de publicações 19\% ( $\mathrm{N}=768)$ foram realizadas em áreas protegidas, distribuídas por 27 países do Continente Americano. A América do Sul foi a região com maior número de trabalhos ( $\mathrm{N}=356 ; 46 \%)$, seguida pela América do Norte $(\mathrm{N}=284 ; 37 \%)$ e América Central ( $N=128 ; 17 \%$ ) (Figura 6).

Figura 6. Número de publicações sobre turismo alternativo (período de 1973 a 2017) em áreas protegidas por Américas (Sul, Norte e Central)

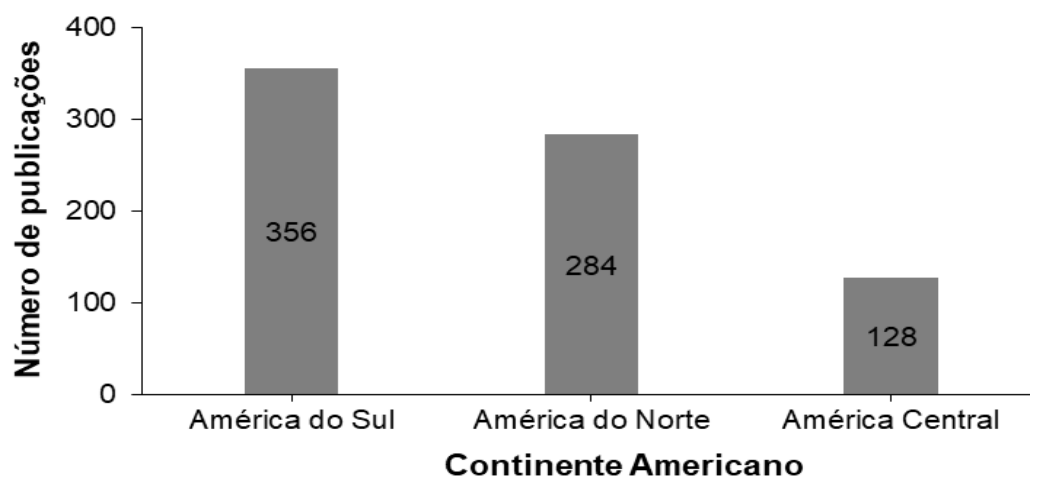

Segundo o relatório da IUCN, a América do Sul é a cobertura mais ampla alcançada ao nível regional, onde 4,85 milhões de $\mathrm{km} 2$ (24\%) de terra estão protegidos e metade desse montante (2,47 milhões de $\mathrm{km} 2)$ fica no Brasil, ao ponto de ser considerado a maior rede nacional de áreas protegidas terrestres do mundo (IUCN, 2016).

Geralmente o turismo alternativo se desenvolve em áreas remotas ou regiões protegidas que apresentam expressiva beleza cênica, interesse ecológico e importância cultural, essas áreas são criadas para a contenção da perda em grande escala de ecossistemas naturais em vez de desenvolvê-las para outros fins como agricultura, exploração madeireira e pecuária. Desta forma, as florestas e os animais representam maior valor econômico se mantidos em pé e vivos, conservados para observação turística do que se explorados de forma predatória (Medeiros et al., 2021; Wearing \& Neil, 2014).

O Parque Nacional é a categoria de área protegida com maior número de publicações ( $N=551 ; 72 \%)$, seguida da Reserva da Biosfera $(\mathrm{N}=58 ; 8 \%)$ e da Floresta Nacional ( $\mathrm{N}=36 ; 5 \%)$ (Figura 7).

O Parque Nacional é o mais popular e antigo entre as categorias de Unidades de Conservação de Proteção Integral (categoria II pela IUCN) que têm como dever preservar ecossistemas de grande relevância ecológica e beleza cênica, possibilitando a realização de pesquisas científicas, realização de atividades educacionais e de interpretação ambiental, recreação e turismo ecológico (IUCN, 2016). Pela sua ampla distribuição e por permitirem a visitação pública, as Unidades de Conservação propiciam a maior variedade de experiências e importante interação entre o visitante e a natureza (Maretti, Catapan, Abreu \& Oliveira, 2012; Medeiros et al., 2021). 
Figura 7. Número de publicações sobre turismo alternativo (período de 1973 a 2017) em áreas protegidas por categoria de Unidade de Conservação segundo o SNUC

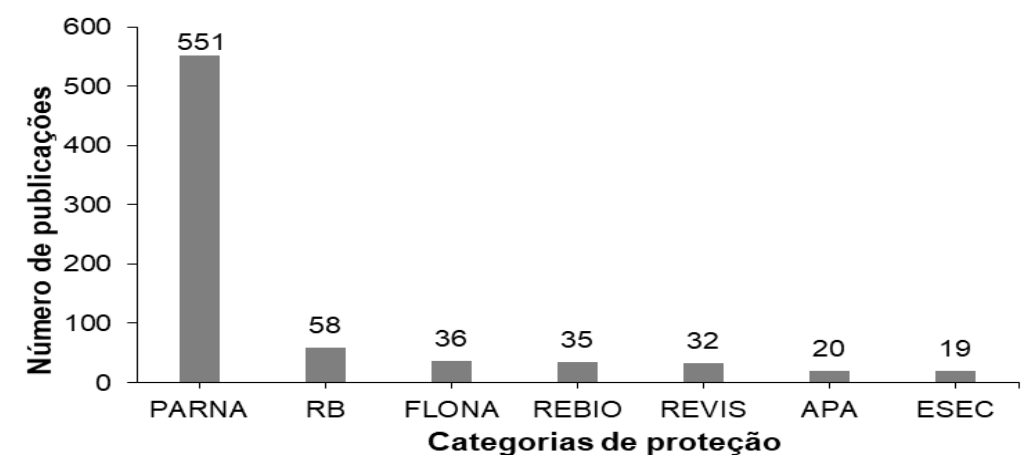

Nota: PARNA= Parque Nacional; RB= Reserva da Biosfera; FLONA= Floresta Nacional; REBIO= Reserva Biológica; REVIS= Refúgio da Vida Silvestre; APA= Área de Proteção Ambiental; ESEC= Estação Ecológica.

Além dos países das Américas, a figura do Parque Nacional existe também no Continente Africano, Europeu e Oceania e dentre as atividades permitidas estão precipuamente o turismo e a pesquisa científica. No Reino Unido, por exemplo, as pessoas podem residir dentro das áreas de parques, assim como na Austrália, onde povos aborígenes estão assentados e em alguns casos é possível a exploração econômica de petróleo, madeira e mineração com autorização dos órgãos competentes (Spinola, 2013).

O Brasil optou pelo modelo norte-americano de gestão dos seus Parques Nacionais e trouxe, através do SNUC, o veto de permanência das populações tradicionais nas suas áreas, justificado pelo princípio de que não há equilíbrio entre os interesses antrópicos e a proteção do meio ambiente (Spinola, 2013). Assim, a geração de renda com o turismo alternativo é o aliado mais viável para a manutenção econômica destas áreas.

No Brasil, em 2015, a visitação de Unidades de Conservação chegou a mais de oito milhões de turistas, um aumento de 9,6\% (765 mil visitas) em relação ao ano anterior (7,3 milhões), sendo o Parque Nacional da Tijuca, no estado do Rio de Janeiro e o Parque Nacional de Foz do Iguaçu, estado do Paraná, os responsáveis por mais de 1 milhão de visitas cada (Ministério do Turismo do Governo Federal do Brasil, 2015; Souza, Thapa, Rodrigues \& Imori, 2017).

O gerenciamento destas áreas é um grande desafio, pois as Unidades de Conservação Federais estão distribuídas por todos os estados brasileiros do território terrestre e do bioma marinho costeiro e conservam uma rica biodiversidade, com patrimônios naturais, históricos e culturais, além de serem espaços estratégicos para a reprodução social de brasileiros que moram dentro ou no entorno delas (Souza et al., 2017).

\subsection{Temáticas abordadas}

Os trabalhos abordaram diversas temáticas $(\mathrm{N}=49)$, as mais frequentes foram: impactos do turismo $(\mathrm{N}=595 ; 14,4 \%)$, conservação e preservação $(\mathrm{N}=469 ; 11,3 \%)$ e atrativos naturais $(\mathrm{N}=398 ; 9,6 \%)$ (Figura 8). 
Figura 8. Principais abordagens das publicações sobre turismo alternativo no Continente Americano (período de 1973 a 2017)

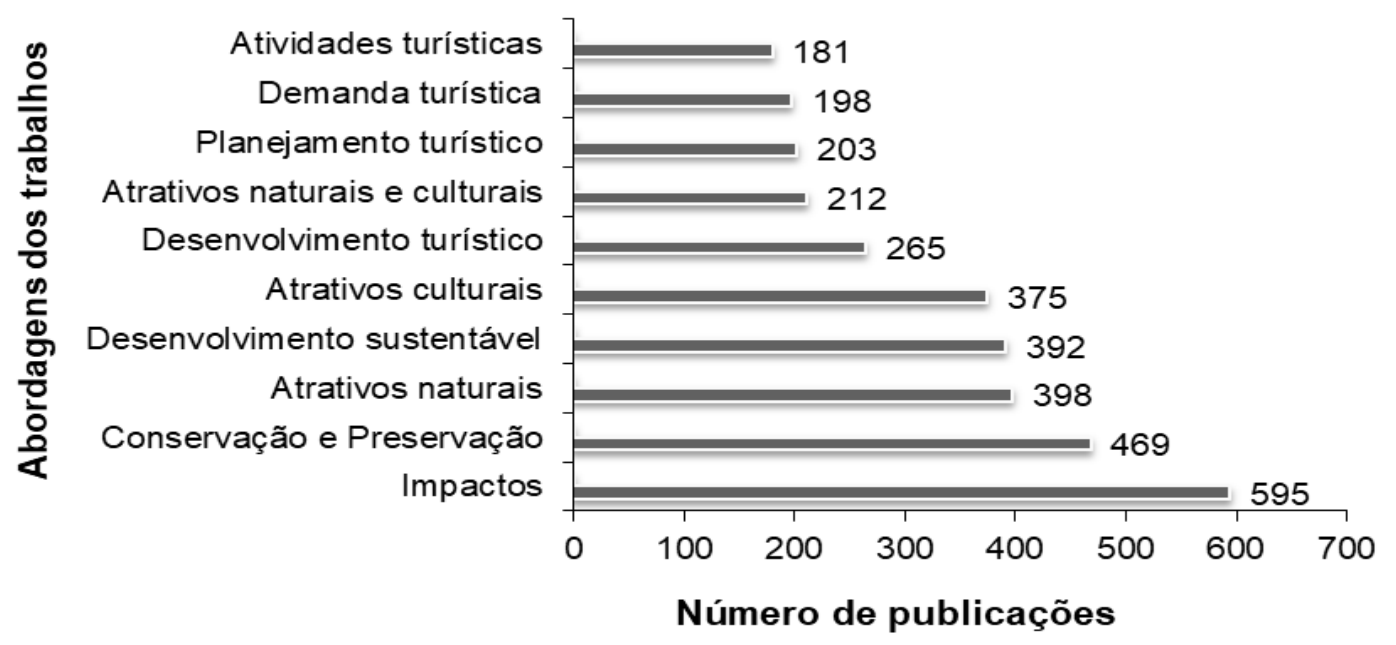

Para a OMT (2003), os impactos do turismo resultam das diferenças sociais, econômicas e culturais entre a população residente e os turistas, e da exposição aos meios de comunicação social. O turismo impacta muitos setores da economia, pois essa atividade implica a compra e venda de produtos (ex.: alimentação) e serviços (ex.: hotelaria), gera renda (ex.: contratação de funcionários para restaurantes e hotéis), fomenta a arrecadação de impostos e a ligação aos setores. Um turista que paga pelos equipamentos turísticos está contribuindo para beneficiar outras atividades comerciais e contribui para o desenvolvimento da economia local.

O turismo já teve o rótulo de "indústria limpa", porém causa impactos no meio natural e na cultura das comunidades e povos (Bartholo Junior, Delmaro \& Badin, 2005). Os impactos do turismo começaram a ser investigados na segunda metade da década de 1970, em consequência do auge das atividades do turismo de massa, de modo a mostrarem que seu crescimento levaria a insustentabilidade ambiental (Dias, 2005).

Trata-se ainda de uma atividade que durante todo o ano, mundialmente, mobiliza milhões de pessoas e, consequentemente, gera impactos sociais, culturais, econômicos e ambientais nas comunidades receptoras. A participação e o envolvimento de setores sociais são essenciais para fortalecer a identidade local (Ministério do Turismo do Governo Federal do Brasil, 2007). Para tanto, é necessário a atuação efetiva do Estado como articulador dos setores que compõem a sociedade e que são atingidos pela atividade turística, com o objetivo de promover uma gestão compartilhada, ou seja, o setor privado, as organizações sociais e a comunidade precisam deliberar sobre o assunto (Salvati, 2004).

\subsection{Meio ambiente e componente impactado}

O meio ambiental mais estudado foi o antrópico $(\mathrm{N}=2.826 ; 40 \%)$, seguido do biótico $(\mathrm{N}=2.285$; $33 \%$ ) e abiótico ( $\mathrm{N}=1.887 ; 27 \%$ ) (Figura 9a). Dentre os meios ambientais, o componente mais 
relacionado com impactos foi a água $(\mathrm{N}=1.618 ; 17 \%)$, seguido de cultura $(\mathrm{N}=1.304 ; 14 \%)$ e fauna $(\mathrm{N}=1.302 ; 14 \%)$ (Figura 9b).

Figura 9. a) Meios Ambientais estudados e b) componente impactado segundo as publicações sobre turismo alternativo no Continente Americano (período de 1973 a 2017)
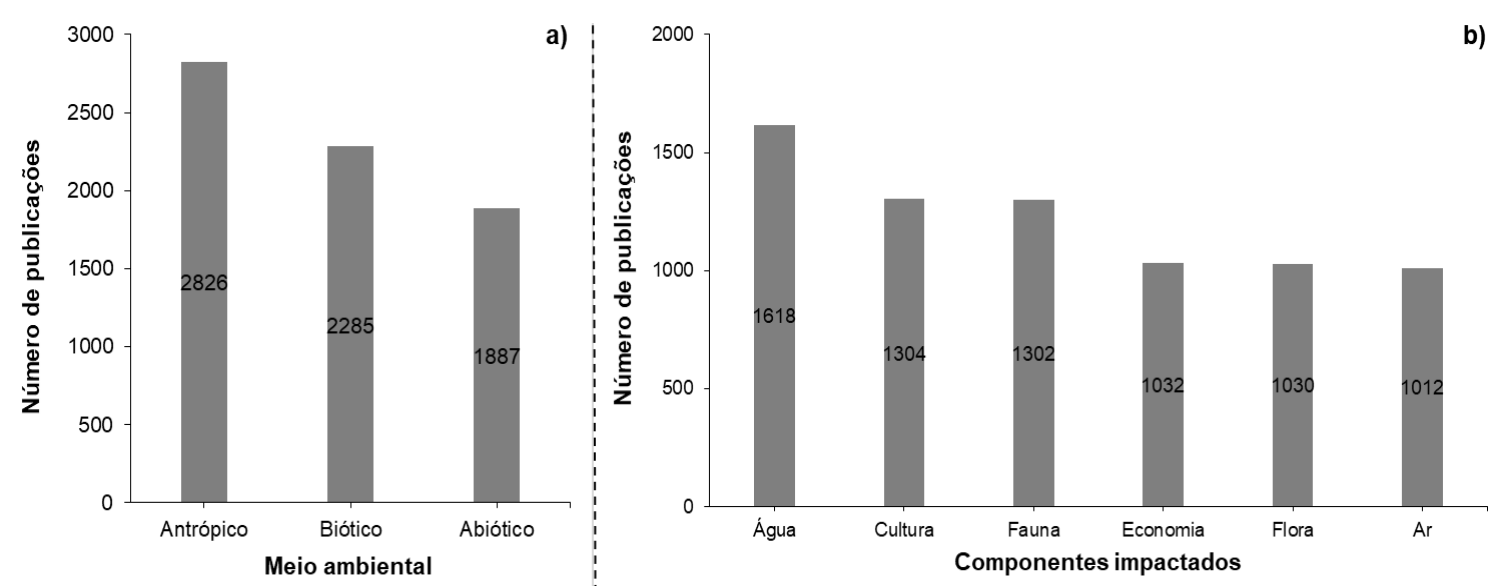

De forma geral, os aspectos que influenciam a qualidade do meio ambiente estão interrelacionados, como as questões éticas, políticas, sociais, econômicas, científicas, tecnológicas, culturais e ecológicas (Ministério do Turismo do Governo Federal do Brasil, 2007).

O meio antrópico aparece principalmente através do componente cultura. Os estudos relacionados com impactos culturais levam mais tempo para aparecer e são menos tangíveis, como se referem a mudanças qualitativas podem ser sutis e difíceis de mensurar (Lage \& Milone, 2009). A cultura é o vetor que torna possível conhecer as particularidades de uma determinada região ou localidade e de um dado momento histórico, sendo possível atuar na preservação da identidade cultural das comunidades e populações tradicionais eventualmente afetadas pela atividade turística (Marujo, 2014).

Os meios biótico e abiótico integram os ambientes naturais que proporcionam formas de recreação e lazer, contemplação de paisagens, observação de animais em vida livre, seus abrigos, ninhos e locais de descanso e alimentação. No meio biótico o componente fauna foi o mais pesquisado. No turismo alternativo voltado para a natureza, se encontram várias atividades, como a observação de animais, os safáris fotográficos e os estudos científicos. $O$ ambiente natural constitui a base principal de incremento e sustentabilidade da atividade (Dias, 2005).

Muitos parques e santuários de vida selvagem têm sido criados para proteger espécies carismáticas consideradas símbolos nacionais e atrações turísticas, como é o caso do Santuário Comunitário dos Babuínos em Belize, criado com o intuito de concentrar esforços para a conservação da vida silvestre daquele país (Sonaglio, 2006). Outro exemplo é o Projeto TAMAR (Tartarugas Marinhas), que tem como compromisso a pesquisa, a conservação e o manejo de cinco espécies de tartarugas marinhas que ocorrem no Brasil e está presente em nove estados com potencial turístico (Lima, Neto \& Holanda, 2018). 
Do meio abiótico, o componente água apresentou-se como mais impactado dentre os outros componentes, pois os ambientes aquáticos compõem uma das principais opções de lazer de turistas (Dias \& Granado, 2014). Esta preferência é evidenciada pelos estudos que investigaram a fauna e flora aquática e as percepções de impactos em zonas costeiras (Carvalho, 2010; Ferreira, 2011; Spalding et al., 2017).

Os ecossistemas aquáticos são essenciais para a preservação da biodiversidade fluvial marinha e para a sobrevivência humana. O planeta terra é constituído por mais de 70\% de água, porém apenas $1 \%$ dessa água doce encontrada em lagos, calotas polares, rios e reservatórios subterrâneos está disponível para o consumo humano, por isso é importante seu uso racional e preservação desses ecossistemas, inclusive para o lazer (Ministério do Turismo do Governo Federal do Brasil, 2018b).

Desta forma o turismo alternativo é uma das formas de conscientização e conservação dos recursos hídricos, pois a água é o principal atrativo de vários destinos turísticos das Américas, como, por exemplo, as Cataratas do Niágara, localizada entre os Estados Unidos e Canadá; o rio Celeste, na Costa Rica; a Rede de Reservas dos Recifes da Barreira, no Belize; as ilhas Galápagos, no Equador; e a Amazônia, no Brasil, esta última reconhecida pela UNESCO como patrimônio natural da humanidade, devido sua importância para a biosfera (UNESCO, 2003).

\subsection{Caráter dos impactos ambientais}

Existe uma diferença significativa entre o caráter dos impactos ambientais abordados nos artigos sobre turismo alternativo no Continente Americano $(F(3,119)=2.985 ; p=0.034)$ (Figura 10). Foram identificados 2.898 artigos que abordaram apenas os impactos positivos, 868 somente os impactos negativos, 206 impactos positivo/negativo e 165 artigos não relataram nenhum impacto (Figura 10 ).

O desenvolvimento da atividade turística provoca impactos ambientais positivos e/ou negativos, envolvendo o ambiente natural, o ambiente transformado e o ambiente sociocultural (Fandé \& Pereira, 2014). Os impactos positivos do turismo são: geração de renda, emprego, desenvolvimento econômico, valorização e empoderamento feminino, conservação da herança cultural e áreas naturais, trocas culturais e renovação do orgulho cultural, aumento da qualidade e do conhecimento ambiental, envolvimento com o meio ambiente e melhoramento da infraestrutura sob a perspectiva do desenvolvimento sustentável (Rezende \& Rezende, 2006).

Não foi observada diferença significativa entre os trabalhos que apontaram impactos negativos e positivos em simultâneo, em relação aos trabalhos que não abordaram impactos, estes não apresentaram nenhum tipo de impacto, pois tratavam de conceituações e revisões do turismo.

Os impactos têm origem num processo de mudança, consequência da interação do turista, da comunidade e do meio receptor, muitas vezes tipos parecidos de turismo provocam impactos diferentes que vão depender da natureza e da sociedade nas quais ocorrem (Ruschmann, 2003). Conforme a autora, a avaliação dos impactos de toda ordem sobre o meio ambiente é difícil, por cinco razões: 1) o homem está vivendo e modificando a 
terra há milhares de anos, dificultando o estabelecimento de uma base para medir as modificações que não são só turísticas; 2 ) é impossível separar o papel do homem da natureza; 3) as complexas interações do turismo fazem com que o impacto total da atividade seja quase impossível de medir; 4) um espaço de tempo transcorrerá até que todos os impactos de uma atividade se tornem aparentes; e 5) difícil identificar as variáveis a considerar na indicação das mudanças provocadas pelo turismo e a atribuição de valores aos indicadores selecionados, pois a importância dos impactos varia em cada sistema estudado (Mathieson \& Wall, 1988; Ruschmann, 2003).

Figura 10. Caráter dos impactos ambientais abordados nas publicações sobre turismo alternativo no Continente Americano (período de 1973 a 2017)

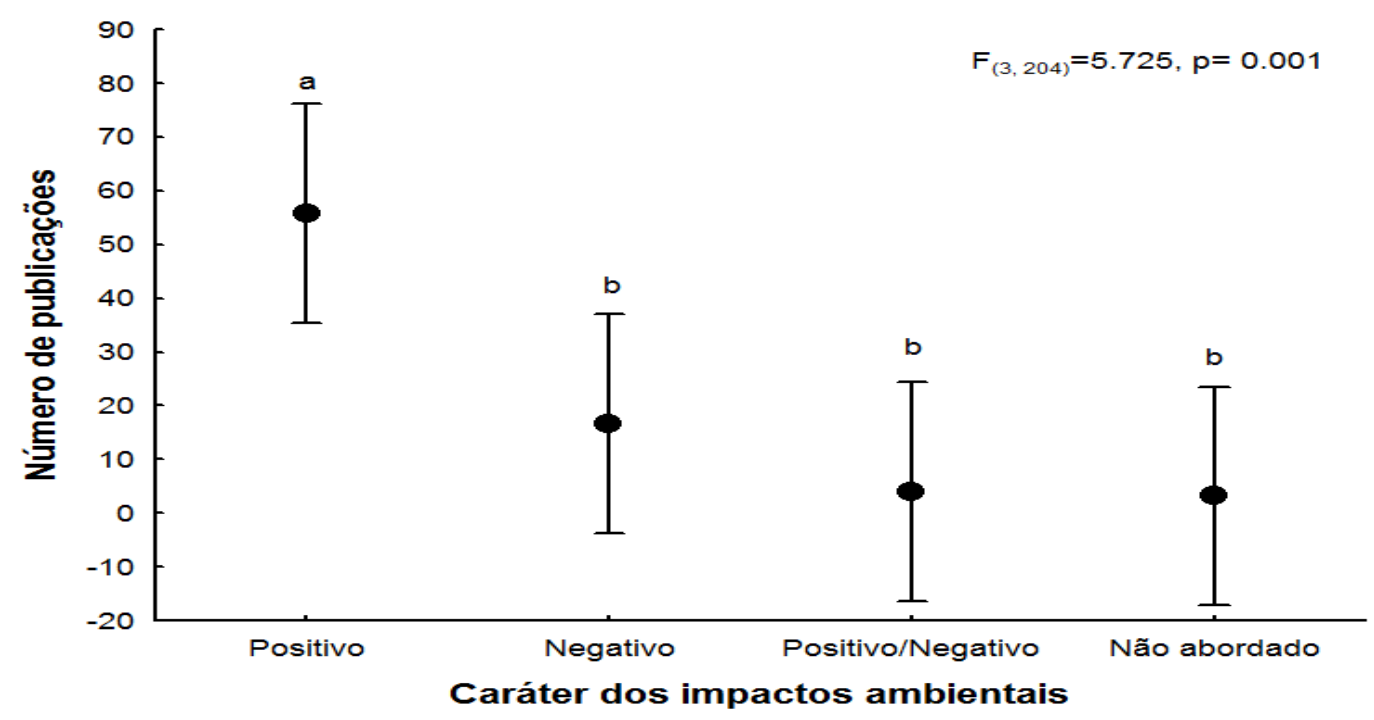

O turismo é dinâmico e os seus impactos e consequências mudam constantemente. Então, o seu monitoramento periódico se torna necessário no sentido de minimizar os impactos negativos, aperfeiçoar os positivos e enriquecer a experiência vivencial das pessoas que viajam e das pessoas que recebem esse turista (Ruschmann, 2003).

\section{Considerações finais}

Todos os países do Continente Americano foram alvos de pesquisas sobre o turismo alternativo, indicando a universalização das atividades turísticas sustentáveis.

O aumento progressivo no número de artigos reflete o crescente interesse sobre o tema e a importância dessa atividade econômica. Eventos e declarações com alcance mundial, como a Conferência das Nações Unidas sobre Meio Ambiente e Desenvolvimento, fomentam a produção de conhecimento sobre o turismo alternativo.

Os países com maior número de pesquisas sobre o turismo alternativo (Estados Unidos e Brasil) são locais que abrigam atrativos naturais ímpares, boa infraestrutura turística e maior quantidade territorial de áreas protegidas. 
A quantidade de trabalhos que estudaram somente os impactos positivos do turismo alternativo foi maior. Esse tipo de turismo também gera impactos negativos no ambiente que precisam ser considerados nas pesquisas. Estudos que analisam os impactos ambientais são importantes para nortear práticas voltadas para a preservação e conservação do meio natural, além de sinalizar a necessidade de ações mitigadoras para o local.

Por fim, os resultados obtidos nesse trabalho revelam a necessidade de mais estudos sobre os impactos negativos do turismo alternativo em todos os componentes do meio ambiente (antrópico, biótico e abiótico). A forma de planejar e fazer o turismo alternativo de modo a obter a sustentabilidade é outra linha de investigação que merece atenção dos pesquisadores, assim como, cabe uma análise cienciométrica de experiências bem-sucedidas com o turismo alternativo. Adicionalmente, vale ressaltar que, observa-se nas publicações que o turismo responsável se opõe ao turismo de massa, ou outros segmentos turísticos que não são compatíveis com o desenvolvimento sustentável.

\section{Referências}

Andreu-Boussut, V. \& Salin, E. (2018). Le tourisme dans les Amériques: Territoires, expériences et nouveaux enjeux? IdeAs - Idées d'Amériques. doi: 10.4000/ideas.5691

Akaishi, F. M. (2003). Aplicação de biomarcadores de contaminação ambiental em estudos de laboratório e monitoramento em campo (Dissertação de mestrado não publicado). Universidade Federal do Paraná, Curitiba.

Alberton, A \& Lopes, V. J. (2007). Um estudo sobre a pesquisa em turismo no Brasil: Análise de dois periódicos Qualis/Capes. In Seminário da Associação Nacional de Pesquisa e Pós-graduação em Turismo, IV, 2007. Anais do IV Seminário da Associação Nacional de Pesquisa e Pós-Graduação em Turismo. São Paulo: Editora Aleph. CD-ROM.

Alves, M. T. R., Teresa, F. B. \& Nabout, J. C. (2014). A global scientific literature of research on water quality indices: Trends, biases and future directions. Acta Limnologica Brasiliensia, 26(3), 245-253. doi: 10.1590/S2179-975X2014000300004

Barbosa, F. T. \& Souza, D. A. (2010). Frequência do uso adequado nos testes estatísticos nos artigos originais publicados na Revista Brasileira de Anestesiologia entre janeiro de 2008 e dezembro de 2009. Revista Brasileira de Anestesiologia, 60(5), 528-536. doi: 10.1590/S003470942010000500009

Barrio, A. M. C., Maquiera, Y. M., Fernández, I. M. V. \& Chavez, E. S. (2020). Impactos de la práctica del turismo alternativo, en la gestión del área protegida Parque Nacional Viñales, Pinar Del Río, Cuba. Revista Eletrônica da Associação dos Geógrafos Brasileiros Seção Três Lagoas, 1(31), 12-47. Disponível em: https://periodicos.ufms.br/index.php/RevAGB/article/view/10001

Bartholo Junior, R., Delmaro, M. \& Badin, L. (Orgs) (2005). Turismo e sustentabilidade no Estado do Rio de Janeiro. Rio de Janeiro: Garamond.

Beni, M. C. (2017). Análise estrutural do turismo. $13^{\mathrm{a}}$ ed. São Paulo: SENAC.

Bertuzzo, G. M. P. (2004). Produção científica: Um estudo cienciométrico do periódico Turismo em Análise. Anais do Seminário de Pesquisa em Turismo do Mercosul - Semintur: Caxias do Sul/RS. Disponível em: https://www.ucs.br/site/midia/arquivos/30-producao-cientifica.pdf 
Bringas, R., N. L. \& González A., J. I. I. (2004). El turismo alternativo: Una opción para el desarrollo local en dos comunidades indígenas de Baja California. Economía, Sociedad y Territorio, IV(15), 551590. Disponível em: https://www.redalyc.org/pdf/111/11101508.pdf

Bufrem, L. \& Prates, Y. (2005). O saber científico registrado e as práticas de mensuração da informação. Ciência da Informação, Brasília, 34(2), 9-25. doi: 10.1590/S0100-19652005000200002

Carvalho, S. M. S. A. (2010). Percepção do turismo por parte da comunidade local e dos turistas no município de Cajueiro da Praia-PI. Turismo em Análise, 21(3), 470-493. doi: 10.11606/issn.19844867.v21i3p470-493

CIET [Centro de Investigaciones y Estudios Turísticos]. (2015). Estudios y perspectivas en turismo. Disponível em: http://www.estudiosenturismo.com.ar

Coriolano, L. N. \& Sampaio, C. A. C. (2012). Discursos e concepções teóricas do desenvolvimento e perspectivas do turismo como indução. In M. D. S. Brasileiro, J. C. Medina \& L. N. Coriolano (Orgs), Turismo, cultura e desenvolvimento (pp.49-73). Campina Grande: EDUEPB.

Costa, C. M. M. (2016). A evolução nas publicações sobre turismo de natureza nas revistas brasileiras de turismo: Uma análise cienciométrica (monografia de bacharelato). Brasília: Universidade de Brasília.

Dias, G. M. \& Granado, D. C. (2014). Lazer e recreação associados aos ambientes aquáticos numa pequena cidade do interior paulista. Colloquium Humanarum, 11, 678-686. doi: 10.5747/ch.2014.v11.nesp.000590

Dias, R. (2003) Turismo sustentável e meio ambiente. São Paulo: Atlas.

Dias, R. (2005). Introdução ao turismo. São Paulo: Atlas.

Faco, R. A. (2013). Turismo, sustentabilidade e a gênese de um "ecoturismo": Uma análise dos trabalhos do EcoUc/CONECOTUR (dissertação de mestrado). Sorocaba: Universidade Federal de São Carlos.

Fandé, M. B. \& Pereira, V. F. G. C. (2014). Impactos ambientais do turismo: Um estudo sobre a percepção de moradores e turistas no Município de Paraty-RJ. REGET/UFSM - Revista Eletrônica em Gestão, Educação e Tecnologia Ambiental, 18(3), 1170-1178. doi: 10.5902/2236117013864

Fennell, D. (2003). Ecotourism. Nova lorque: Routledge.

Ferreira, P. F. M. (2011). Diagnóstico dos impactos socioambientais urbanos em Itacaré (BA) (dissertação de mestrado não publicada). Universidade Estadual de Campinas/Instituto de Geociências: Campinas/SP.

Figueiredo-Filho, D. B. \& Silva Júnior, J. A. (2009). Desvendando os mistérios do coeficiente de correlação de Pearson (R). Revista Política Hoje, 18(1), 115-146.

Gunter, U., Ceddia, M. G., Leonard, D. \& Tröster, B. (2018). Contribution of international ecotourism to comprehensive economic development and convergence in the Central American and Caribbean region. Applied Economics, 50(33), 3614-3629. doi: 10.1080/00036846.2018.1430339

Güzeller, C. O. \& Çeliker, N. (2018). Bibliometric analysis of tourism research for the period 2007-2016. Advances in Hospitality and Tourism Research, 6(1), 1-22. doi: 10.30519/ahtr.446248

Hallal, D. R. \& Müller, D. (2014). A Embratur e os cursos superiores de turismo no Brasil (1970-76). Revista Rosa dos Ventos 6(2), 164-17.

ICT [Instituto Costaricense de Turismo]. (s.d). Anuário estatístico 2017. Disponível em: https://www.ict.go.cr/es/

IUCN [InternationI Union for Conservation of Nature]. (2016). Protected area categories. Disponível em: https://www.iucn.org/theme/protected-areas/about/protected-area-categories 
Jafari, J. \& Aaser, D. (1988). Tourism as the subject of doctoral dissertations. Annals of Tourism Research, Menomomie, 15(3), 407-429. doi: 10.1016/0160-7383(88)90030-8

Klak, T. (2007). Sustainable ecotourism development in Central America and the Caribbean: Review of debates and conceptual reformulation. Geography Compass, 1(5), 1037-1057. doi: 10.1111/ j.17498198.2007.00055.x

Lage, B. H. G. \& Milone, P. C. (2009). Economia do Turismo. São Paulo: Atlas.

Leão, V. A. (2018). A importância do cálculo de capacidade de carga turística. Disponível em: https://viajarverde.com.br/capacidade-de-carga-turistical

Lima, L. P. Q., Neto, L. D. \& Holanda, L. A. (2018). Programa de ecoturismo e educação ambiental do projeto Tamar - Fernando De Noronha: Uma análise de 2013 a 2016. Revista Brasileira de Ecoturismo, 11(1), 47-60. doi: 10.34024/rbecotur.2018.v11.6658

Macias-Chapula, C. A. (1998). O papel da informetria e da cienciometria e sua perspectiva nacional e internacional. Ciência da Informação, 27(2), 134-140. doi: 10.1590/So10019651998000200005

Maretti, C. C., Catapan, M. I. S., Abreu, M. J. P. \& Oliveira, J. E. D. (2012). Áreas protegidas: Definições, tipos e conjuntos - reflexões conceituais e diretrizes para gestão. In Gestão de Unidades de Conservação: Compartilhando uma experiência de capacitação. WWF-Brasil/IPÊ- Instituto de Pesquisas Ecológicas. Organizadora: Maria Olatz Cases. WWF-Brasil.

Mariutti, F. G., Giraldi, J. M. E. \& Crescitelli, E. (2013). The image of Brazil as a tourism destination: An exploratory study of the American market. International Journal of Business Administration, 4(1), 13-22. doi: 10.5430/ijba.v4n1p13

Marôco, J. (2018). Análise estatística com o SPSS statistic. Portugal: Report Number.

Marujo, N. (2014). A cultura, o turismo e o turista: Que relação? Revista de Investigación en turismo y desarrollo local, 7(16). Disponível em: https://www.researchgate.net/publication/263460043

Mathieson, A. \& Wall, G. (1988). Tourism - economic, physical and social impacts. Longman: London.

Medeiros, H. M. N., Guerreiro, Q. L. M., Vieira, T. A., Silva, S. M. S., Renda, A. I. S. A. \& Oliveira-Junior, J. M. B. (2021). Alternative Tourism and Environmental Impacts: Perception of Residents of an Extractive Reserve in the Brazilian Amazonia. Sustainability 13(4), 2076. doi: 10.3390/su13042076

Meng, Z., Jun, Y. \& Zhengzheng, W. (2009). Reflections on the connotations of ecotourism. Chinese Journal of Population Resources and Environment, 7(2), 67-70. doi: 10.1080/10042857.2009.10684926

Ministério do Turismo do Governo Federal do Brasil. (2007). Programa de regionalização do turismo Roteiros do Brasil: Turismo e sustentabilidade. Coordenação geral de regionalização. Secretaria Nacional de Políticas de Turismo. Departamento de Estruturação, Articulação e Ordenamento Turístico. Brasília: Coordenação Geral de Regionalização.

Ministério do Turismo do Governo Federal do Brasil. (2010). Ecoturismo: Orientações básicas. Ministério do Turismo, Secretaria Nacional de Políticas de Turismo, Departamento de Estruturação, Articulação e Ordenamento Turístico, Coordenação Geral de Segmentação. Brasília: Ministério do Turismo. doi: 10.13140/2.1.1176.9283

Ministério do Turismo do Governo Federal do Brasil. (2015). Programa turismo sustentável e infância, (TSI).

Ministério do Turismo do Governo Federal do Brasil. (2018a). Desembarques internacionais.

Ministério do Turismo do Governo Federal do Brasil (2018b). Água e turismo sustentável. 
Mooghali, A., Alijani R., Karami, N. \& Khasseh, A. A. (2011). Scientometric analysis of the scientometric literature. Internacional Journal of Information Science and Management, 9(1), 19-31. Disponível em: https://ijism.ricest.ac.ir/index.php/ijism/article/view/89

Nicacio, G. \& Juen, L. (2015). Chironomids as indicators in freshwater ecosystems: An assessment of the literature. Insect Conservation and Diversity, 8, 393-403. doi: 10.1111/icad.12123

OMT [Organização Mundial do Turismo]. (2003). Guia de desenvolvimento do turismo sustentável. (Trad. S. Netz). Porto Alegre: Bookman/OMT.

OMT [Organização Mundial do Turismo]. (2017). UNWTO Annual Report 2016. UNWTO, Madrid. doi: $10.18111 / 9789284418725$

OMT [Organização Mundial do Turismo]. (2018). Faits saillants OMT du tourisme, édition 2018. OMT, Madrid. doi: 10.18111/9789284419913

Pechlaner, H., Zehrer, A., Matzler, K. \& Abfalteral, D. (2004). A ranking of international tourism and hospitality journals. Journal of Travel Research, 42(4), 328-332. doi: 10.1177/0047287504263026

Pereira, I. R., D’Abadia, P. L., Prado, A. D. L., Matos, F. S., Nabout, J. C., Gonçalves, P. J. \& Almeida, L. M. (2018). Trends and gaps in the global scientific literature about Jatropha curcas $L$. (Euphorbiaceae), a tropical plant of economic importance. Semina. Ciências Agrárias, 39(1), 7-18. doi: 10.5433/1679-0359.2018v39n1p7

Pieri, V. S. G. (2014). Fluxos turísticos internacionais: Uma proposta metodológica de análise sobre os (novos) destinos. Revista Turismo em Análise, 25(3), 503-526. doi: 10.11606/issn.19844867.v25i3p503-526

Pimentel, T. D., Carvalho, F. C. C. \& Oliveira, M. C. B (2018). Centros de pesquisa em turismo no Mercosul: Distribuição, ênfases e possíveis interações como fator de desenvolvimento. Revista GUAL, Florianópolis, 11(1), 319-342. doi: 10.5007/1983-4535.2018v11n1p319

Penerliev, M. (2017). Alternative tourism in Bulgaria - general characteristics. Espaço e Economia, 10. doi: 10.4000 / espacoeconomia.2921

Pires, P. S. (2017). Dimensões do ecoturismo. São Paulo: SENAC.

Puccini, L. R. S., Giffoni, M. G., Silva, L. F. \& Utagawa, C. Y. (2015). Comparativo entre as bases de dados PubMed, SciELO e Google Acadêmico com o foco na temática Educação Médica. Cadernos UniFOA, 10(28), 75-82.

Quintana, V. M. (2017). El turismo de naturaleza: Un producto turístico sostenible. Arbor, 193(785), 114. doi: 10.3989/arbor.2017.785n3002

R Development Core Team. (2015). R: A language and environment for statistical computing. R Foundation for Statistical Computing, Vienna, Austria. Disponível em http://www.R-project.org/

Rejowski, M. (1993). Pesquisa acadêmica em turismo no Brasil (1975 a 1992): Configuração e sistematização documental (Tese de doutoramento não publicada). Escola de Comunicações e Artes/Universidade de São Paulo: São Paulo.

Rezende, C. F. \& Rezende, D. C. de (2006). Impactos do turismo: Uma análise sob a ótica da população receptora. In Anais do X Colóquio Internacional sobre Poder Local. Salvador, Bahia. Disponível em http://www.anpad.org.br/admin/pdf/enanpad2005-apsc-2576.pdf

Ruschmann, D. V. M. (2003). Turismo e planejamento sustentável: A proteção do meio ambiente. Papirus: Campinas-SP.

Salvati, S. S. (Org.) (2004). Turismo responsável - Manual de Políticas Públicas. Brasília, DF: WWF Brazil.

Shen, Y., Morrison, A. M., Wu, B., Park, J., Li, C., \& Li, M. (2018). Where in the world? A geographic analysis of a decade of research in tourism, hospitality, and leisure journals. Journal of Hospitality \& Tourism Research, 42(2), 171-200. doi: 10.1177 / 1096348014563394 
Shimano, Y., Salles, F. F. \& Juen, L. (2013). Study of the mayfly order Ephemeroptera (Insecta) in Brazil: A scienciometric review. Revista Brasileira de Entomologia, 57(4), 359-364. doi: 10.1590/S008556262013005000043

Sonaglio, K. E. (2006). A transdisciplinaridade no processo de planejamento e gestão do ecoturismo em Unidade de Conservação (Tese de doutoramento). Programa de pós-graduação de Engenharia Ambiental, Universidade Federal de Santa Catarina, Florianópolis.

Souza, T. V. S. B., Thapa, B.; Rodrigues, C. G. O. \& Imori, D. (2017). Contribuições do turismo em unidades de conservação federais para a economia Brasileira - Efeitos dos gastos dos visitantes em 2015. Sumário Executivo. ICMBio. Brasília. Disponível em:

https://www.icmbio.gov.br/portal/images/stories/edital/ ontribuições_do_turismo_em_ucs_federais_para_a_economia_brasileira.pdf

Souza, T. V. S. B.; Simões, H. B.; (2018). Contribuições do Turismo em Unidades de Conservação Federais para a Economia Brasileira - Efeitos dos Gastos dos Visitantes em 2017: Sumário Executivo. ICMBio. Brasília.

Spalding, M., Burke, L., Wood, S. A., Ashpole, J., Hutchison, J., \& Ermgassen, P. (2017). Mapping the global value and distribution of coral reef Tourism. Marine Policy, 82, 104-113. doi: 10.1016/j.marpol.2017.05.014

Spaolonse, E. \& Martins, S. S. O. (2016). Ecoturismo: Uma ponte para o turismo sustentável. Revista Brasileira de Ecoturismo, 9(6), 684-698. doi: 10.34024/rbecotur.2016.v9.6554

Spinola, C. A. (2013). Parques nacionais, conservação da natureza e inserção social: Uma realidade possível em quatro exemplos de cogestão. Revista Turismo Visão e Ação, 15(1), 71-83. doi: 10.14210/rtva.v15n1.p071-083

Trigo, L. G. G. (2005). Análises regionais e globais do turismo brasileiro. São Paulo: Roca.

UNESCO [United Nations Educational, Sicentific and Cultural Organization]. (2003). World Heritage List - Central Amazon Conservation Complex. Disponível em https://whc.unesco.org/en/list/998/

UNESCO [United Nations Educational, Sicentific and Cultural Organization]. (2017). A UNESCO e o ano internacional do turismo sustentável. Disponível em http://www.unesco.org/new/pt/brasilia/about-this-office/prizes-and-celebrations/2017international-year-of-sustainable-tourism

Vanti, N. A. P. (2002). Da bibliometria à webometria: Uma exploração conceitual dos mecanismos utilizados para medir o registro da informação e a difusão do conhecimento. Brasília, 31(2), 152162. doi: $10.1590 /$ S0100-19652002000200016

Zhang, S., Lyu, P. \& Yan, Y. (2015). Global geographical and scientometric analysis of tourism-themed research. Scientometrics, 105(1), 385-401. doi: 10.1007/s11192-015-1678-3

Wearing, S. \& Neil, J. (2014). Ecoturismo, impactos, potencialidades e possibilidades. Barueri, São Paulo: Manole.

HELOISE MICHELLE NUNES MEDEIROS é bacharel em Turismo pelo Instituto Esperança de Ensino Superior, no ano de 2007. É especialista em Gestão Ambiental e Desenvolvimento Sustentável pela Uninter, no ano de 2016. Em 2019, concluiu o mestrado em Sociedade, Ambiente e Qualidade de Vida (Biodiversidade, saúde e Sustentabilidade) pela Universidade Federal do Oeste do Pará. Desde 2014, trabalha na Universidade Federal do Oeste do Pará, no cargo de Assistente Administrativa do curso de Gestão Ambiental do Instituto de Ciências e Tecnologia das Águas. Os seus interesses de investigação incluem avaliação de impactos do turismo, ecoturismo, turismo alternativo, sustentabilidade e 
percepção ambiental. Endereço institucional: Campus da Ufopa Santarém (Unidade Tapajós), Rua Vera Paz, s/n, Bairro Salé, Santarém 68040-255, Pará, Brasil. ORCID: 0000-0001-8837-4848

QUÊZIA LEANDRO DE MOURA GUERREIRo é bacharel em Ciências Ambientais pelo Centro Universitário do Estado do Pará, no ano de 2009. É especialista em Ciências Forenses. Conclui o mestrado (em 2012) e o doutorado (em 2017) em Ciências Ambientais (Ecossistemas Amazônicos e Dinâmicas Socioambientais) pela Universidade Federal do Pará, Museu Paraense Emílio Goeldi e a Empresa Brasileira de Agropecuária. Desde 2014, leciona diversas disciplinas os cursos Bacharelado em Gestão Ambiental, Bacharelado em Engenharia Sanitária e Ambiental para e Bacharelado interdisciplinar em Ciências e Tecnologia das Águas, todos ofertados pela Universidade Federal do Oeste do Pará, Santarém, Brasil, onde desempenha atualmente a função de Professora Adjunta II. Os seus interesses de investigação incluem gestão ambiental, turismo sustentável, gestão de unidades de conservação, ecologia e conservação de ecossistemas continentais, educação ambiental e avaliação de impactos ambientais. Endereço institucional: Campus da Ufopa Santarém (Unidade Tapajós), Rua Vera Paz, s/n, Bairro Salé, Santarém 68040-255, Pará, Brasil. ORCID: 0000-0002-4382-1250

JoSÉ MAX BARBOSA OLIVEIRA-JUNIOR licenciou-se em Ciências Biológicas na Faculdade Araguaia, no ano de 2010. É especialista em Perícia e Auditoria Ambiental, Engenharia Ambiental e Indicadores de Qualidade, Licenciamento Ambiental e Direito Ambiental. Em 2013, concluiu o mestrado em Ecologia e Conservação pela Universidade do Estado de Mato Grosso. Em 2015, concluiu o doutorado em Zoologia na Universidade Federal do Pará e Museu Paraense Emílio Goeldi com a apresentação de uma tese sobre efeitos espaciais, ambientais e morfológicos na estruturação da comunidade de Odonata (Insecta) em igarapés na Amazônia brasileira. Entre 2019 e 2020, desenvolveu um pós-doutoramento no Centro de Ciências do Mar da Universidade do Algarve. Desde 2014, leciona diversas disciplinas nos cursos Bacharelado em Gestão Ambiental, Bacharelado em Engenharia Sanitária e Ambiental e Bacharelado interdisciplinar em Ciências e Tecnologia das Águas no Instituto de Ciências e Tecnologia das Águas da Universidade Federal do Oeste do Pará, Santarém, Brasil, onde desempenha atualmente a função de Professor Adjunto II. Os seus interesses de investigação incluem ecologia e conservação de ecossistemas aquáticos continentais, avaliação de impactos ambientais, insetos aquáticos, bioindicadores e ciência cidadã. Endereço institucional: Campus da Ufopa Santarém (Unidade Tapajós), Rua Vera Paz, s/n, Bairro Salé, Santarém 68040-255, Pará, Brasil. ORCID: 0000-0002-0689$205 \mathrm{X}$

Submetido em 23 de junho de 2020

Aceite em 19 de fevereiro de 2021 